\title{
INFANTILE DIARRHOEAL DEHYDRATION TREATED WITH ADRENAL CORTICAL HORMONE AND POTASSIUM CHLORIDE*
}

\author{
BY \\ WILlIAM EMDIN, M.D., D.P.H., Ph.D., B.A. \\ From Cape Town, South Africa
}

(Received for Publication, October 4, 1949)

\begin{abstract}
Dehydration is the danger signal of infantile diarrhoea because without dehydration the mortality from properly treated gastro-enteritis should be negligible, hence the importance of preventing dehydration and the recognition that its presence indicates a medical emergency. Important constituents of both extracellular and intracellular body fluids are the electrolytes, and Gamble (1947) considers the term 'dehydration' incomplete because it fails to indicate, as was shown by McIntosh, Kadji, and Meeker (1931), that water loss is always accompanied by loss of electrolyte. It follows that therapeutic repair cannot be effective unless both water and electrolyte are replaced.
\end{abstract}

Electrolytes are dissociated within the body; for example, sodium chloride is present as separate sodium ions and chloride ions. With diarrhoea there is an excessive excretion of water, protein, chloride, sodium and bicarbonate ions (mainly extracellular electrolytes), and potassium and magnesium ions (mainly intracellular electrolytes). Over 30 years ago Holt, Courtney, and Fales (1915) showed that diarrhoeal stools contain much larger amounts of water and electrolyte than do normal stools, and they expressed the view that a better solution than the Ringer's and normal saline then in use could be devised for parenteral therapy. Prolonged electrolyte loss produces dehydration (Gamble, 1947; Darrow, 1944; Darrow, 1947a); this was confirmed experimentally in animals by Darrow and Yannet (1935). Until recently the cell membrane was believed to be impermeable to the passage of electrolyte and that therefore only extracellular electrolyte could be replaced. Darrow and others found, however, that potassium and sodium do penetrate cell membranes. This led to the introduction by Darrow of his sodium-potassiumchloride solution as a therapeutic measure for the replacement of intracellular as well as extracellular

* A paper read at the 37 th South African Medical Congress, Cape Town, in September, 1949. electrolyte (Govan and Darrow, 1946; Butler et al., 1946).

The acidosis which so commonly accompanies diarrhoeal dehydration is a chloride acidosis (Hartman, 1928; Hamilton et al., 1929). This is associated with a fall in blood bicarbonate and a loss via the stools of a fixed base, i.e. sodium, potassium, calcium, and magnesium (Hoag and Marples, 1931). It is possible that a decrease of cellular potassium may contribute towards acidosis since it is known that the depleted potassium tends to be replaced within the cells by sodium, leaving an excess of chloride ions in the extracellular fluid (Darrow, 1947a). Rapoport and Dodd (1947) stress the importance of giving calcium in the post-acidotic phase. There is no indication that magnesium needs replacing.

Regulation of sodium and chloride metabolism and water balance is a function of the adrenal cortex hormone, and desoxycorticosterone is the active principle (Grollman, 1939). The adrenalectomized animal loses body fluid, sodium, and chloride (Harrop, Soffer et al., 1933; Harrison and Darrow, 1938), and administration of cortical extract reverses this process although large doses may cause a fall in the serum potassium level. Synthetic desoxycorticosterone has a similar effect (Clinton and Thorne, 1943; Thorne and Firor, 1940; McCullagh and Ryan, 1940) but in addition, toxic symptoms may appear with excessive dosage. Both of these unfavourable effects are minimized however if the subject receives a diet of liberal potassium and low sodium content (Talbot, 1948; Gordon, 1940). Selye (1947) points out that unlike desoxycorticosterone acetate, the natural hormone may be given in very large doses without fear of overdosage phenomena.

The literature contains comparatively few references to the use of the cortical hormone as an hydrating agent. Jaudon $(1946 ; 1948)$ believes that physiological adrenal insufficiency occurs not 
uncommonly in the young infant and he has shown that such babies improve with adrenal hormone therapy. Collis and Majecodunmi (1943) state that the hormone is of value in dehydration with ketosis; Miller (1941) found that the physiological weight loss of the newborn infant was less after the use of synthetic cortical extract. In diarrhoeal dehydration, symptoms and blood changes occur which are similar to those seen in adreno-cortical hypofunction (Sullivan, Maclean, and Zwemer, 1932; Aldridge, 1941a). MacLean and his co-workers (1932) consider suprarenal insufficiency to be an aetiological factor in the production of acute intestinal intoxication. Hislop (1938) believes that in marasmus there is ultimately an adrenal hypofunction.

From the literature it would appear that the dehydrated infant should react favourably to adrenal or synthetic desoxycorticosterone and that potassium, apart from its replacement and possible anti-acidotic value, may be a safeguard where the cortical hormone, and especially its synthetic equivalent, is being administered.

The purpose of this paper is to record the result of certain treatments, with special reference to the action of suprarenal cortex extract as an hydrating agent, on a series of 83 infants suffering from diarrhoea with dehydration. The subjects of this investigation were coloured and native babies, and the work was carried out at the Victoria Hospital, Wynberg. Much of the clinical material was of poor quality; because of parental poverty and ignorance many of these infants were malnourished and debilitated before the onset of the diarrhoea for which they were admitted to hospital. All were dehydrated, many severely so, and quite a number had symptoms of toxaemia as well.

\section{Therapeutic Plan}

A basic scheme included treatment with the following preparations, and a graduated scheme of feeding.

Extract of Adrenal Cortex. 'Adrocortin'* (Saphar Laboratories) was the preparation used; each $\mathrm{ml}$. corresponds to the hormone activity of $50 \mathrm{~g}$. of the fresh gland. Therapeutic units of $2 \mathrm{ml}$. were given intramuscularly once or twice daily depending on the severity of the case. A few special cases received three injections per day.

Sodium-Potassium-Chloride ('Darrow's') Solution. Darrow's formula (1947b) was concentrated for convenience to:

Sodium chloride, $32 \mathrm{~g}$; ; potassium chloride, $21 \cdot 6 \mathrm{~g}$.; sodium bicarbonate, $35 \cdot 2 \mathrm{~g}$; water to 1 litre. One

* The author is indebted to Messrs. Saphar Laboratories, Ltd., of Johannesburg, for their generosity in supplying the "Adrocortin' used for this investigation. tablespoonful ( $\frac{1}{2} \mathrm{oz}$.) of this mixture was added to each pint of $5 \%$ glucose solution.

Feeding. It was considered advisable to use milk of reduced fat content in order to counteract fat intolerance. 'Dryco,' $\dagger$ a powdered milk, was the product used in this instance. Liquified 'Dryco' of full strength obtained by dissolving one part in seven parts water, has the following composition:

Fat, $1.5 \%$; protein, $4 \%$; lactose, $5.7 \%$; mineral salts, $0.9 \%$; water, $87 \cdot 9 \%$ (manufacturer's analysis).

Fluid Replacement and Milk Mixtures. In the basic scheme fluids were given orally, and to make up the fluid already lost 3 to $3 \frac{1}{2} \mathrm{oz}$. per lb. body weight per day was the standard aimed at. During the first 24 hours of treatment Darrow's solution only was given. Then the infant received a 'Dryco' mixture, five feeds per day, at the usual four-hourly intervals. As it was considered preferable not to use very weak milk mixtures (Emdin, 1948), the initial 'Dryco' mixture was of halfstrength with $4 \%$ carbohydrate added in the form of dextri-maltose. Of this the baby was offered $2 \mathrm{oz}$. per feed if under $8 \mathrm{lb}$. in weight, and 3-4 oz. if above this weight, the fluid deficit being made up by giving Darrow's solution between feeds. With progress, the quantity of each feed was increased to $4 \mathrm{oz}$. for the lighter and $6 \mathrm{oz}$. for the heavier baby. In the second stage of dietetic treatment, the mixture was changed to two-thirds of the full strength, and later 'Dryco' was replaced by a mixture of two-thirds cows' milk and one-third water; $4 \%$ carbohydrate was added in each instance. The milk mixtures were not acidified. Finally the cows' milk formula was adjusted in accordance with the infant's age, and where indicated, the diet was completed by giving cereals, vegetables, etc. Darrow's solution was continued for two weeks, being then replaced by $5 \%$ glucose in water. Vitamins were offered in the second week of treatment.

The subjects under review were graded clinically on a basis of dehydration into mild and severe cases, the severely dehydrated babies being further classified into (a) cases showing little or no symptoms of toxicity, and (b) those in which intestinal intoxication was present or became established later. For the purpose of treatment the 83 cases were divided into two groups. To Group 1 (49 patients), the therapeutic scheme was applied. Group 2 (34 patients) was used for comparison with certain cases in Group 1; these infants received the same mineral salts and milk mixtures as the babies of Group 1 but 'Adrocortin' was omitted from the treatment scheme (with certain exceptions) and in addition, the very toxic patients were given parenteral fluids by the intravenous route. The infants who developed complicating infections such as bronchitis, pneumonia, otitis media, abscesses, etc., were treated with penicillin where necessary. Sulphonamides were not used.

Results of Treatment in Mild Dehydration

Group 1: Basic Therapeutic Scheme Applied (11 Cases). These infants were in much better condition than the

t The Borden Co. 
severely dehydrated babies to be described later, but nevertheless, all showed evidence of dehydration, such as loss of tissue turgor and skin elasticity (especially on the lower abdomen and thighs), depressed fontanelle, dry mouth and tongue, thirst, oliguria, etc. The body weights averaged one-third less than the normal weights for age, and in most cases diarrhoea and vomiting had begun from four to seven days before admission. Five of these babies had symptoms of mild toxaemia: coldness of the extremities, irritability, restlessness, periodic bouts of purposeless crying; two patients exhibited a tendency to stare fixedly.

The babies did well and fluids were taken eagerly from the start. 'Adrocortin' was administered once daily to seven of these infants and twice daily to four. The shortest period for which the hormone was given was three days and the longest, twelve days. The arithmetical average was six days. Response to treatment was immediate and satisfactory. By the third day the babies were more active and contented, food and fluids were taken well, vomiting had ceased. Relapse occurred in one case and this coincided with an attack of bronchitis; the diarrhoea was quickly controlled by Darrow's solution and 'Dryco.' There were no deaths.

The most striking change for the better was noted where toxic symptoms were present. In these cases all signs of toxicity had disappeared after only 48 hours' treatment. The babies rapidly became vigorous and active and there was clinical evidence of fluid fixation in the body.

Group 2: 'Adrocortin' Omitted from the Basic Scheme (11 Cases). These babies were of the same type as those described above and four of them exhibited symptoms of commencing toxaemia. Although there was little difficulty with Darrow's solution, the feeds were taken more reluctantly by this group than was the case where the adrenal hormone was being administered. All recovered and only two cases relapsed. In these infants compared with those in Group 1 the response to treatment and the clinical improvement was slower at first and the recovery phase was more protracted. The difference in therapeutic response was most evident in the toxic cases. With hormone therapy, the toxic symptoms were alleviated within 48 hours, whereas without 'Adrocortin' several days elapsed before a parallel degree of improvement was attained.

\section{Results of Treatment in Severe Dehydration}

In studying the effects of treatment on 61 babies with severe diarrhoeal dehydration, special attention was given to the action of the suprarenal cortical hormone. Almost every child in this series was grossly under weight, the average weight for age being 60 to $55 \%$ of the normal. Most of the cases on 'Adrocortin' received two injections a day for 10 to 14 days.

Group 1(a): No Toxicosis (21 Cases). These babies were treated in accordance with the basic therapeutic scheme. Two to four days after the beginning of treatment there was evidence of fluid replacement. Dryness of the mouth and tongue had been alleviated, the babies were lively and cheerful, and the subcutaneous tissues began to fill out: first the lower abdomen, then the face, and lastly the tissues of the thighs. Vomiting was mild and soon disappeared. Transient setbacks occurred in a few of these patients but most of them continued to improve and gained weight gradually but steadily. Two babies in this group died. One succumbed to bronchopneumonia after complete recovery from the diarrhoea, and the other died suddenly four days after admission to hospital. Permission for a necropsy in the latter case was refused.

The clinical impression was that the cortical hormone played an important part in reversing the process of dehydration. The following table records the gain in weight after four weeks of treatment of 11 malnourished and dehydrated babies with acute diarrhoea in that vulnerable age period, the first six months of life. The general improvement was more striking than the gains in weight would indicate.

\section{Gain in Weight of Eleven Dehydrated Babies With DIARRHOEA}

\begin{tabular}{|c|c|c|c|}
\hline $\begin{array}{l}\text { Case } \\
\text { No. }\end{array}$ & $\begin{array}{l}\text { Age on } \\
\text { Admission } \\
\text { (months) }\end{array}$ & $\begin{array}{c}\text { Weight } \\
\text { on } \\
\text { Admission }\end{array}$ & $\begin{array}{l}\text { Weight after } \\
4 \text { Weeks of } \\
\text { Treatment }\end{array}$ \\
\hline $\begin{array}{l}\text { 1. B.F. } \\
\text { 2. M.M. } \\
\text { 3. E.M. } \\
\text { 4. H.S. } \\
\text { 5. F.B. } \\
\text { 6. G.A. } \\
\text { 7. J.E. } \\
\text { 8. N.A. } \\
\text { 9. H.M. } \\
\text { 10. E.W. } \\
\text { 11. I.S. }\end{array}$ & $\begin{array}{l}2 \frac{1}{2} \\
3 \\
3 \frac{1}{2} \\
3 \frac{1}{2} \\
3 \frac{1}{2} \\
4 \\
5 \\
5 \frac{1}{2} \\
6 \\
6 \\
6\end{array}$ & 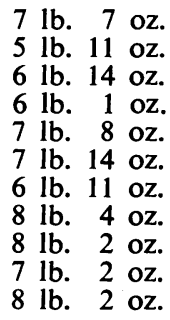 &  \\
\hline
\end{tabular}

* Ten days later this infant weighed $7 \mathrm{lb} .2 \frac{1}{2} \mathrm{oz}$.

Group 1(b): Toxicosis Present (17 Cases). Symptoms of intestinal intoxication ranged from extreme irritability to drowsiness, stupor, fixed stare, head retraction, and other manifestations similar to those seen in disease of the nervous system. The infants in this group were difficult to manage. Fluids and feeds were taken badly and some of the infants had to be fed by pipette or tube. The greater the initial toxicity, the more frequent were the setbacks and difficult periods. .With patient nursing, however, these babies could be coaxed to take fluids and the milk mixture. Vomiting was a constant feature and when persistent became a problem of importance.

In spite of these difficulties, some degree of improvement occurred in most of these babies, but only after four or five days of treatment. Three of the babies, after the usual hesitant beginning, picked up well and made uninterrupted recoveries. The remainder, however, exhibited a tendency to retrogress, and even where the eventual outcome was satisfactory there were times when anxiety was felt regarding the immediate prognosis. Four patients, after initial improvement, had a relapse of such severity that fluids were given intravenously as 
an emergency measure; these cases are included in the next section of this work. There were seven deaths.

It was evident that some measure of rehydration was taking place. Even where death occurred the final episode was almost invariably preceded by a stage of temporary betterment.

The following records indicate that toxic cases may benefit when the hormone is given in larger dosage:

CASE 12. M.B. Four days' history of vomiting and diarrhoea with loss of $2 \frac{1}{2} \mathrm{lb}$. in weight. On admission: age, 10 months; weight, $13 \frac{1}{2} \mathrm{lb}$. Vomiting became uncontrollable and therapy was apparently ineffective. Injections of the hormone were increased to three a day; vomiting became less frequent and ceased three days later.

CASE 13. F.M. On admission: age, 9 months; weight, $10 \frac{1}{4} \mathrm{lb}$. After initial improvement, severe toxic symptoms appeared. Three hormone injections per day were given instead of two, with immediate improvement. Five days later 'Adrocortin' could be discontinued.

CASE 14. B.K. On admission: age, 15 months; weight, $16 \mathrm{lb}$. On the third day the child became very toxic. 'Adrocortin' was increased to three injections per day. There was rapid amelioration of symptoms and disappearance of dehydration.

CASE 15. I.J. On admission: age, 3 months; weight, $5 \mathrm{lb}$. Very dehydrated; moderately toxic. Temporary improvement on two injections of hormone; gain of $10 \mathrm{oz}$. in ten days. Sudden relapse with the appearance of severe toxic symptoms and drop in weight to $5 \mathrm{lb}$. Dosage of 'Adrocortin' was increased to $6 \mathrm{ml}$. per day with good results. One month later the infant weighed $7 \mathrm{lb}$.

CASE 16. F.L. On admission: age, 14 months; weight, $14 \frac{1}{4} \mathrm{lb}$. Moderately toxic. Two days later severe toxic symptoms appeared and the weight became $12 \frac{3}{4} \mathrm{lb}$. Hormone injections were increased to three per day. At first there was little change, but four days later the toxic symptoms began to recede. The weight rose rapidly and 12 days after admission it was $15 \mathrm{lb} .6 \mathrm{oz}$.

All these patients made a good recovery. In each case the retrogression was of such severity as to warrant the introduction of parenteral fluid therapy. Instead, the dosage of hormone was increased, apparently with good effect. It should be noted, however, that these five cases differed from the others in this group in that at first toxic symptoms were only moderately severe, becoming aggravated later.

Group 2: Intravenous Fluids (23 Cases). In order to assess the degree of hydration effected by hormone therapy in severe diarrhoeal dehydration without toxic symptoms, the therapeutic scheme minus 'Adrocortin' could have been applied to controls. Experience teaches that the reliance upon oral fluids without additional measures for combating dehydration in marasmic diarrhoea is likely to result in a high death rate. Such controls were not used because of the risks involved, particularly as the clinical results in the non-toxic infants were proving so informative.

Where the basic scheme was applied to infants with alimentary intoxication, however, the results were not so promising. It was decided therefore to compare rehydration resulting from hormone therapy plus oral fluids, with that following parenteral replenishment of body fluids. The adopted parenteral method was transfusion by intravenous drip of normal saline and $5 \%$ glucose in water (Levine, 1945). As the chloride content tends to be high in dehydration (Aldridge, 1941b), saline was given in restricted quantity for the purpose of replacing sodium. It was found that, as others have reported (Rapoport and Dodd, 1946), the drip may be continued for several days, with safety and profit to the child. Where indicated, small serum or blood transfusions were given as well, but only after the acute dehydration had been relieved. In addition, these infants were offered Darrow's solution by mouth and 'Dryco' feeds.

All except eight cases in this group, four of the eight being transfers from Group 1, were admitted with advanced toxaemia. Generally speaking, the response to intravenous fluid therapy was prompt, although not necessarily sustained, and there was rapid amelioration of the toxic symptoms. Compared with similar cases in Group 1, feeds were taken sooner and more readily. Where the feeds were refused or vomiting persisted, the transfusion was of particular value. Some of these babies, apparently progressing favourably while being transfused, began to retrogress as soon as the drip was discontinued. For this reason, it was found advisable to extend rather than to curtail the infusion period. Although three to five days of transfusion was adequate for most cases, the drip was administered for as long as 13 days where necessary. The most important difference between parenteral fluid and hormone rehydration was the greater rapidity with which dehydration was relieved and toxic symptoms were alleviated when the intravenous route was used. Direct replacement of fluid appeared to be the method of choice for the immediate treatment of alimentary intoxication. Eight deaths occurred.

In the post-toxic phase, two problems arose (1) the tendency to dehydration as soon as the drip was discontinued, and (2) failure to gain weight. The following cases indicated that the suprarenal hormone may convert hydrolability into hydrostability:

CASE 17. L.M. On admission: age, 8 months; weight, $14 \frac{1}{2} \mathrm{lb}$.; very toxic. After three days of transfusion the drip was discontinued. Dehydration recurred. A second transfusion was given for three days and then stopped. Again the infant retrogressed. At this point 'Adrocortin' was administered; there was immediate improvement with no further loss of fluid.

CASE 18. E.D. On admission: age, 3 months ; weight, $8 \mathrm{lb}$.; very toxic. On intravenous drip for seven days. Although the infant's condition improved, the weight remained stationary during the next 14 days. Adrenal hormone was now given; the weight gradually increased and six weeks later the child was discharged, weighing $9 \mathrm{lb}$.

CASES 19 AND 20. The two cases were similar. Infants M.S. and A.M. on admission were 15 months old and weighed 15 and $15 \frac{1}{2} \mathrm{lb}$. respectively. Both toxic; A.M., semi-comatose. Both improved with parenteral fluids; M.S. was on the drip for seven days, and A.M. for 
13 days. The body weight remained stationary after initial small gains. 'Adrocortin' was then administered. Three weeks later, the one child weighed $16 \mathrm{lb}$. $9 \mathrm{oz}$., and the other $17 \mathrm{lb}$.

\section{Discussion and Conclusions}

There are paediatricians who advocate prolonged fasting in the first stage of the treatment for gastroenteritis. In my opinion, the marasmic infant should not be deprived of food for longer than 24 or at the most 48 hours, because this type of baby is already severely malnourished and continued starvation must further weaken the infant's resistance. Recent work by Chung and Viščorová $(1948 \mathrm{a} ; 1948 \mathrm{~b})$ indicates that food restriction is unnecessary in the treatment of infantile diarrhoea. The use of milk mixtures equivalent to not less than half-strength cows' milk proved to be satisfactory; carbohydrate may be added but it is advisable to reduce the fat because a mixture with a high fat content is likely to aggravate the diarrhoea.

Darrow (1947a; 1948) and Donaldson (1947) report that clinical improvement follows the oral or parenteral administration of potassium chloride to babies with gastro-enteritis. As regards the present investigation, the only cases from which conclusions could be drawn in this connexion were the 11 mildly dehydrated infants of Group 2, as these babies were given Darrow's solution and 'Dryco' only. These patients did exhibit a state of well-being superior to that usually seen in similar cases treated without potassium. Further, I have used potassium chloride in the treatment of over 100 cases of infantile diarrhoea without dehydration; compared with controls of $5 \%$ glucose solution, the general condition and stools of these babies improved much more rapidly and there were fewer relapses (unpublished work). Potassium by mouth is safer than by injection because of the danger of cardiac embarrassment when the serum potassium is too high. No symptoms of intoxication were noted when potassium was given orally for 14 days; in fact none appeared, when it was continued experimentally for a month in a few cases. Darrow's solution was taken eagerly on the whole, and more readily than glucose solution.

The adrenal cortical hormone is a powerful hydrating agent. It is valuable as a therapeutic measure in diarrhoeal dehydration, especially in the acute form with commencing toxicosis. In marasmus its rehydrating action is gradual but nevertheless effective, provided that severe toxic symptoms are absent. Where there is alimentary intoxication, fluid fixation through the medium of the cortical hormone is too slow; in such cases fluids should be administered parenterally. Although five very toxic infants recovered when given larger doses of hormone, one is not justified in assuming on such few cases that even massive hormone therapy is necessarily a substitute for parenteral fluids, especially in intestinal intoxication where prompt rehydration is so urgent a matter. The hydrostabilizing effect of the hormone may be utilized to promote gain in weight or to complete the process of rehydration where parenteral fluid therapy alone has not been entirely successful. In this investigation it was found that 2 to $6 \mathrm{ml}$. per day of the cortical extract was sufficient to promote adequate hydration when given for 10 to 14 days in severe cases and for half that period in mild cases.

\section{Summary}

This paper reports on the value of adrenal cortical extract and other measures in the treatment of infantile diarrhoea with dehydration.

Eighty-three cases are reviewed. The degree of dehydration varied; some of the infants had toxic symptoms in addition.

Potassium chloride solution was given orally with good effect.

Dietetically, it is recommended that after a short fasting period, milk mixtures of low fat content be offered.

The suprarenal cortical hormone is valuable for treating dehydration and for promoting gain in weight. Where intestinal intoxication is present, however, parenteral fluids should be given immediately; later, the adrenal hormone may be administered in order to promote fluid fixation in the body.

\section{REFERENCES}

Aldridge, A. G. V. (1941a). Arch. Dis. Childh., 16, 81. (1941b). Arch. Dis. Childh., 16, 182.

Butler, A. M., Talbot, N. B., Crawford, J. D., MacLachlan, E. A., and Appleton, J. (1946). Amer. J. Dis. Child.,72, 481.

Chung, A. W. (1948a). J. Pediat., 33, 1.

- , and Viščorová, B. (1948b). J. Pediat., 33, 14.

Clinton, M., and Thorne, G. W. (1943). Bull. Johns Hopk. Hosp., 72, 255.

Collis, W. R. F., and Majecodunmi, M. A. (1943). Brit. med. J., 1, 31.

Darrow, D. C. (1944). Ann. Rev. Physiol., 6, 95.

- (1947a). Tex. Rep. Bio. Med., 5, 29.

- (1947b). 'Outline for Treatment for Severe Diarrhoea with Dehydration.' Thesis presented at Yale University Medical School.

(1948). Brenneman's Practice of Paediatrics, Vol. 1, Chap. 28. Hagerstown.

- and Yannet, H. (1935). J. clin. Invest., 14, 266.

Donaldson, G. (1947). Arch. Dis. Childh., 22, 180.

Emdin, W. (1948). S. Afr. med. J., 22, 313.

Gamble, J. L. (1947). 'Chemical Anatomy, Physiology and Pathology of Extracellular Fluid.' Harvard University Press. Cambridge, Mass. 
Gordon, E. S. (1940). J. Amer. med. Ass., 114, 2549.

Govan, C. D., and Darrow, D. C. (1946). J. Pediat., 28, 541 .

Grollman, A. (1939). J. Pharmacol., 67, 257.

Hamilton, B., Kadji, L., and Meeker, D. (1929). Amer. J. Dis. Child., 38, 314.

Harrison, H. E., and Darrow, D. C. (1938). J. clin. Invest., 17, 77.

Harrop, G. A., Soffer, L. J., Ellsworth R., and Trescher, J. H. (1933). J. exp. Med., 58, 17 .

Hartmann, A. F. (1928). Amer. J. Dis. Child., 35, 557.

Hislop, W. A. (1938). Lancet, 2, 308.

Hoag, L. A., and Marples, E. (1931). Amer. J. Dis. Child., 42, 291.

Holt, E. L., Courtney, A. M., and Fales, H. L. (1915). Amer. J. Dis. Child., 9, 213.

Jaudon, J. C. (1946). J. Pediat., 29, 696. (1948). J. Pediat., 32, 641 .
Levine, S. Z. (1945). J. Pediat., 26, 196.

MacLean, A. B., Sullivan, R. C., and Zwemer, R. L. (1932). Amer. J. Dis. Child., 43, 1277.

McCullagh, E. P., and Ryan, E. J. (1940). J. Amer. med. Ass., 114, 2530.

McIntosh, R., Kadji, L., and Meeker, D. (1931). J. clin. Invest., 9, 333 .

Miller, R. A. (1941). Arch. Dis. Childh., 16, 113.

Rapoport, S., and Dodd, K. (1946). J. Pediat., 29, 758.

- et al. (1947). Amer. J. Dis. Child., 73, 391.

Selye, H. (1947). 'Text Book of Endocrinology.' University of Montreal, p. 158.

Sullivan, R. C., MacLean, A. B., and Zwemer, R. L. (1932). Amer. J. Dis. Child., 43, 1279.

Talbot, N. B. (1948). Brenneman's Practice of Paediatrics, Vol. 1, Chap. 40. Hagerstown.

Thorne, G. W., and Firor, W. M. (1940). J. Amer. med, Ass., 114, 2517. 